\title{
Gender balancing your scholarly journal
}

Ros Attenborough

Scholarly journals are in a position of power when it comes to setting the agenda for an academic field. Journal editors can highlight knowledge trends that they want to encourage, and pass over those they see as less promising. A journal editorial board is typically populated by senior members of the academic community that the journal serves and influences. Because in most academic fields women are under-represented in senior positions, they are also under-represented on editorial boards. This has been documented, for example in medicine (Jagsi et al., 2008); management (Metz et al., 2015); mathematics (Topaz \& Sen, 2016); and environmental studies (Cho et al., 2014). In all of these cases, women occupied less than $20 \%$ of board positions; in mathematics only $8.9 \%$ of editors were women.

These figures are improving, but more slowly than the representation of women in senior academic positions (Metz et al., 2015, p. 712). This is perhaps not surprising because editors themselves are usually responsible for new editor recruitment, drawing on their own extensive but nonetheless partial networks. Gender may not be explicitly considered in these decisions, allowing unconscious bias to flourish. As the journal Nature (2012) admitted in a stunning self-critique, when "thinking about who is doing interesting or relevant work...men most readily come to editorial minds".
However, precisely because editors have such power, there is a great opportunity for top-down change. If you are an editor, reviewer, author, or reader, you can begin steering your favourite academic journal towards a more inclusive future.

This recipe is based on my personal experience as a journal staff member working with editors to improve our board's gender balance. It can also be used for other types of academic board or panel and can be applied to increase representation of ethnic and other minorities, as women are not the only demographic systemically underrepresented in expert boards and panels.

\section{Ingredients}

- Male-dominated academic editorial board.

- Membership of the board, a friend/ colleague who is an editor, or a relationship with the journal via reviewing/authorship/readership.

- Humility and persistence.

\section{Method}

1. Document the gender balance on the board: produce some stats! Editorial board members are usually listed on the journal website.

2. Think about your goal for representation of women on the board. $50 \%$ would be ideal and may be realistic in the 


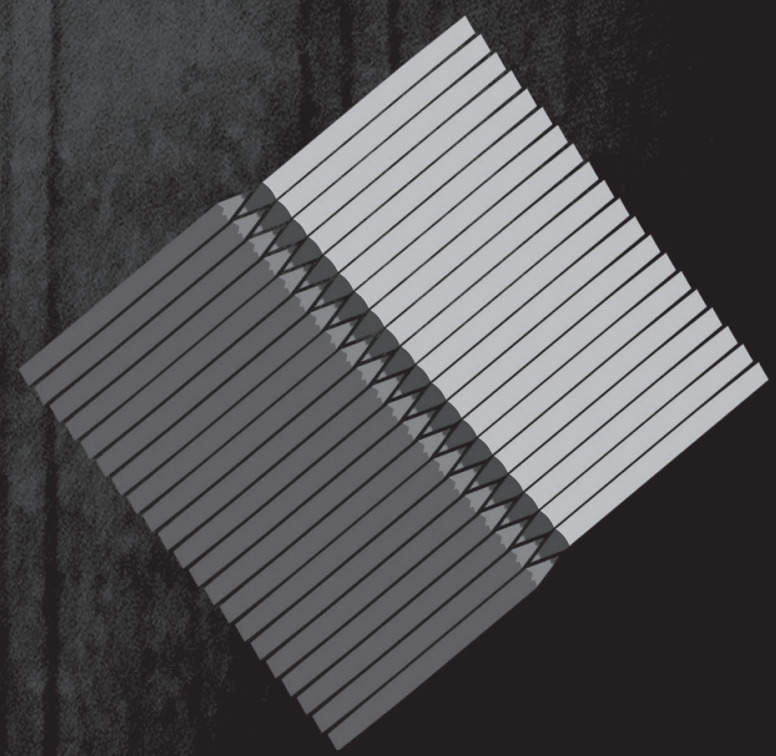

medium term if the existing editorial leadership fully embrace the project. However, short term incremental goals are also valid: to lead from the top down, find out the approximate percentage of women occupying senior positions in your field, and aim for a higher percentage on your board.

\section{If you are an editor with power to} influence the hiring of board members:

- Talk. Talk about gender balance on the board with your colleagues. If you are a man, seek out female colleagues with whom to discuss this issue. Use the board gender statistics to convince them that this is an important issue. Point out that gender imbalance is a growing concern inside and outside academic communities, and it could affect both the quality and reputation of the journal (see http://allmalepanels.tumblr.com/).

- When hiring a new board member, come up with a list. Think hard about the candidates who come to mind. If they are all men, are there any equally qualified women? Don't just rely on your personal

connections; if you don't know of an equally qualified woman, ask your colleagues of all genders, and do some research. Nature (2012) recommends this mental exercise: "Who are the five women I could ask?" Consider hiring a woman over a man if she is equally qualified: this is how you will incrementally redress the imbalance.

- Eventually, establish best-practice guidelines for hiring new editors, so that considering gender equality becomes journal policy rather than your own personal quirk. Be careful here as you do not want to put other editors offside: establishing a policy too quickly or without consultation could make other editors feel like (and thus, be) part of the problem instead of part of the solution.

\section{If you know an editor with power to influence hiring:}

- $\quad$ Again, talk. If you regularly review, publish in, or read the journal, mention that this gender imbalance affects the journal's reputation in your eyes. 
- Ask about their process for hiring new board members. If they do not consider gender in their decisionmaking, share this recipe with them, or just the key message: consciously nominate equally qualified female candidates for any board vacancy. They may also find the article Nature's sexism (Nature, 2012) convincing.

- If things go well, offer your services as an advisor on this issue. Depending on your expertise, you may be able to suggest new female board members of whom the editors were not previously aware.

5. If you don't know an editor, but are a reviewer, author, or reader of the journal then try to find an editor contact on the journal website and follow the steps above.

6. Persist. Gender-balancing your scholarly journal will take some time. You may be discouraged if you encounter resistance, or if nothing seems to be changing. Try to stay with this project by producing new board gender statistics at regular intervals: track any changes and add them to your evidence base. If at first you don't succeed in changing minds with the actions above, try again. Sometimes when nothing seems to be happening, attitudes will slowly be changing.

\section{Cook's tips}

You may encounter difficulties recruiting female editors, even if you are trying. As Arnold (2015) points out, you may find that women decline invitations at a higher rate than men. There are many recipes in the rest of this book that highlight some of the reasons for this and what you can do about it. 